\title{
PARTILHAR PROTAGONISMO: COMUNIDADE INDÍGENA COM SALA MULTISSERIADA E FORMAÇÃO DOCENTE
}

\section{SHARING PROTAGONISM: INDIGENOUS COMMUNITY WITH MULTISERIATE CLASSROOMS AND TEACHER TRAINING}

\author{
Francisco Vanderlei Ferreira da Costa ${ }^{45}$
}

\begin{abstract}
Resumo
Este artigo faz um debate sobre a interação entre a comunidade Pataxó e o Instituto Federal da Bahia (IFBA) para a implementação de uma ação de extensão. O objetivo dessa ação foi promover a formação de professores desta etnia para trabalhar em escolas multisseriadas. Isso foi implementado no ano de 2019 e envolveu uma parceria com três proponentes do município de Porto Seguro: a comunidade Pataxó, a Coordenação indígena da Secretaria Municipal de Educação e o campus do IFBA. A partir do protagonismo da comunidade indígena se discute qual seria o papel da instituição federal de ensino nos programas que envolvem comunidades tradicionais. Trata-se de relato de experiência do coordenador do projeto, em conjunto com uma revisão bibliográfica sobre o tema.

Palavras-chave: Protagonismo. Povos indígenas. Salas multisseriadas.
\end{abstract}

\begin{abstract}
:
This article discusses the interaction between the Pataxó community and the Federal Institute of Bahia (IFBA) in order to implement an extension action that aimed at training teachers of that ethnicity to work in multigrade schools. This action was implemented in 2019 and involved a partnership among three subjects domiciled in the city of Porto Seguro: the Pataxó community, the indigenous Coordination of the Municipal Education Department and the IFBA campus. Based on the debate on the role of the indigenous community, we discuss the role of the federal institution in programs involving traditional communities. This is a bibliographic study based on the author's experience, who participated in the project proposal.
\end{abstract}

Keywords: Protagonism. Indigenous peoples. Multiseriate classrooms.

\footnotetext{
${ }^{45}$ Professor Doutor em Linguística e Língua Portuguesa. Pesquisador e extensionista com sala multisseriada, revitalização e ensino de língua indígena. É professor do Instituto Federal da Bahia. Email: franciscovandof@gmail.com . ORCID:0000-0002-5236-571X. 


\section{RevistAleph}

\section{Contextualizando o debate}

A sabedoria parte da ignorância. Não há ignorantes absolutos. Se num grupo de camponeses conversamos sobre colheitas, devemos ficar atentos para a possibilidade de eles saberem muito mais do que nós (FREIRE, 2011, p. 35).

Envolver a sociedade nas discussões sobre as escolas se apresenta, a cada dia, como uma empreitada de difícil alcance. Tornou-se lugar comum ouvir de professores que a presença de pais nas escolas públicas se reduz ao momento das reuniões de pais, mesmo assim com pouca participação. Assim, a luta para fazer do ambiente escolar um espaço de participação da sociedade se apresenta como um desafio. Nesse caso, mesmo falando da educação básica, é de se supor que sejam necessárias parcerias fortalecedoras da conexão com a comunidade externa.

Se na educação básica essa relação tem se mostrado francamente precária, nas instituições de ensino superior não é diferente. Ou seja, trazer a sociedade para dentro das instituições e também levar as instituições para o seio da sociedade são dois caminhos que se complementam e podem andar juntos ou separados. Se juntos, isso demonstra uma interação mais completa, mais popular e democrática. Se separados, isso mantém a ideia de interação e de não estagnação da relação com os grupos que não estão nas universidades e institutos. Por conseguinte, essa via assume duas posturas, uma seria de mão dupla, nessa a sociedade adentra os muros das instituições e as instituições saem de seus cercados. Seria um movimento fluido. A outra, funciona em uma só direção, mas a entrada da sociedade ou a saída da instituição indica trânsito, consequentemente, possibilidade de mudança.

Dessa forma, a extensão se mostra como mais um caminho para inserir a sociedade nos procedimentos acadêmicos. Não se pode negar que o ensino e a pesquisa também representam espaços que devem ser explorados para essa interação, tendo em vista que os agentes que acessam as demandas nas universidades carregam a bagagem da formação para um mundo exterior, fato que consuma a importância da relação ensino, pesquisa e extensão.

A autora De Medeiros (2017, p. 14) afirma que a extensão pode exercer uma "práxis interativa que alia o conhecimento acadêmico, a educação e a sabedoria popular". Concordamos que essa aliança é muito produtiva e deve ser incentivada, pois trará ganhos (c) (1) (2) 


\section{RevistAleph}

significativos para os entes envolvidos. Contudo, essa relação precisa estar calcada em uma visão crítica, pois todos os envolvidos devem poder acessar a cadeia de comando nos projetos. Caso haja hierarquia na sustentação das bases mantenedoras das ações, haverá perda qualitativa no projeto. Assim, conhecimento acadêmico não deve assumir a postura de definir qual o espaço da educação e, menos ainda, definir como a sabedoria popular deve ser aproveitada. Potencialmente, a sabedoria popular é um canal potente de construção de novos conhecimentos; entretanto, não pode ser vista como um trampolim para se chegar a esses novos conhecimentos.

Os saberes não concebidos nas academias, normalmente, são tratados de maneira pouco respeitosa, subestimados. E como afirma Serrano (2006), em diversos momentos da história das políticas de extensão no Brasil, as ações eram colocadas de maneira vertical. Nessa relação, as comunidades tinham pouco espaço e os estudantes não exerciam seu real potencial de contribuição. Ignorar as comunidades ou envolver poucos estudantes ainda são fatores presentes nas atividades extensionistas. Infelizmente, no ensino e na pesquisa, essa prática de abandono dos sujeitos que são tratados como público alvo, também é recorrente.

Interessa-nos, sobremaneira, essa forma de valorização dos grupos envolvidos nos processos extensionistas. Ao se considerar a participação de outros agentes na proposição de ações de extensão, abrem-se prerrogativas para que as comunidades tradicionais sejam inseridas não somente como o público alvo das propostas, mas como parceiras no desenvolvimento das ações e com voz ativa na definição das temáticas a serem atendidas. Freire (2011, p. 112) nos auxilia nesse compromisso, "não há diálogo, se não há uma intensa fé nos homens. Fé no seu poder de fazer e de refazer. De criar e recriar. Fé na vocação de ser mais, que não é privilégio de alguns eleitos, mas direito dos homens" (grifos do autor). Confiar na possibilidade de parceria é aceitar o diálogo, que virá com as contribuições dos outros participantes.

Este artigo discute a proposição de ação de formação docente, integrando os saberes da comunidade indígena Pataxó e a estrutura formativa do Instituto Federal da Bahia, via projeto de extensão. Ou seja, apresentaremos os processos que envolvem a implementação de um projeto de extensão para o desenvolvimento da educação em comunidades tradicionais. A centralidade do estudo está no envolvimento das comunidades na construção de parcerias para propor e realizar atividades de formação 


\section{RevistAleph}

integral. Dessa forma, o objetivo deste texto é descrever o contexto que permitiu a elaboração de um projeto de extensão para atender demandas de uma comunidade indígena brasileira. A partir dessa conjuntura, haverá um espraiamento para externar a interação, ainda tensionada, entre comunidade indígena e instituições acadêmicas, tendo as turmas multisseriadas o espaço de aplicação dessa experiência.

\section{Tarefa: trabalho em equipe}

A ação de extensão, a sala multisseriada de escola indígena Pataxó em foco: formação docente, teve como marco inicial atividades desenvolvidas, desde 2011, por docentes/pesquisadores do Instituto Federal da Bahia (IFBA) em parceria com a comunidade Pataxó. Assim, a multisseriação tornou-se foco de estudo, dentro dessa instituição, definitivamente, a partir do ano de 2013. Nesse ano, começou o trabalho com produção de material didático para salas com essas especificidades. O trabalho foi dando seus resultados, até que os professores dessa etnia solicitaram a formação continuada, a qual contemplaria todos os docentes que lidassem com as escolas multisseriadas.

A comunidade Pataxó foi, então, proponente dessa proposta de extensão e definiu algumas exigências: além do tema, escola/sala multisseriada, e de envolver todos os docentes desses espaços, também seria um projeto que tivesse como parceiro a Secretaria Municipal de Educação de Porto Seguro na Bahia. Fechava-se o grupo proponente e beneficiário da ação: docentes Pataxó, IFBA, Secretaria Municipal de Educação. Dessa forma, o protagonismo dos indígenas se apresentou também na constituição da equipe que iria trabalhar. Com isso, o passo seguinte foi convidar a seção da respectiva secretaria, responsável pela coordenação indígena, para participar da escrita do projeto.

Essa negociação introdutória foi no ano de 2018, no segundo semestre. O projeto foi escrito, seguindo os trâmites administrativos e pedagógicos do IFBA. Obrigatoriamente, teria registro formal, com certificação da instituição federal. Esse ato foi considerado relevante pelos outros parceiros. Concluíram que dessa maneira haveria uma apropriação do sistema acadêmico para beneficiar a formação. O certificado era importante para algumas práticas sociais que os indígenas também estão subordinados.

No início do primeiro semestre de 2019 , o projeto foi abonado pelos três parceiros e submetido ao sistema de projetos de extensão do IFBA. A participação do movimento 


\section{RevistAleph}

indígenas foi mesclada com a participação da secretaria municipal. Essa mescla aconteceu porque o movimento indígena indica um Pataxó para assumir a coordenação de educação indígena no município de Porto Seguro. Então, ele é representante da secretaria, mas principalmente, representante do movimento indígena. Respeitar essa indicação é fundamental para o andamento das atividades.

Antes da aprovação, porém, havia a necessidade de os entes envolvidos definirem quando e onde aconteceria a formação. O município de Porto Seguro é bastante grande e a maioria das escolas indígenas com salas multisseriadas está afastada da área urbana e também umas das outras. Assim, para encontrar uma metodologia adequada ficou acertado que seriam consideradas algumas especificidades: distância entre as escolas; distância das escolas em relação à Secretaria Municipal de Educação; participantes da formação atuantes em sala de aula; secretaria municipal pediu que não houvesse dispensa dos estudantes para que os docentes pudessem participar da formação; secretaria municipal solicitou horário na formação para discutir os documentos oficiais da educação indígena (tanto aqueles que são preenchidos pelos professores, quanto as diretrizes educacionais municipais); alimentação, hospedagem e transporte. A justificativa para esses três últimos foi que as atividades ocorreriam distantes das residências dos professores indígenas. Esse levantamento foi realizado pelos três entes participantes da parceria.

Ficou definido que a formação aconteceria de maneira rotatória, alternando entre três aldeias. Essas três comunidades foram escolhidas considerando a organização administrativa definida pelo município para agrupar as escolas pataxó. Nessa estruturação, essas escolas foram agrupadas em núcleos a partir de suas localizações geográficas. O revezamento aconteceu, então, entre os núcleos. Cada encontro em uma escola de um dos núcleos. O último encontro deverá acontecer no IFBA. Promover as atividades em núcleos diferentes facilitaria quanto aos gastos com o deslocamento, pois a cada três encontros, um seria em uma comunidade próxima à residência dos cursistas. Ficou definido ainda que haveria dez encontros de dois dias cada um. Os encontros seriam mensais e começariam em agosto de 2019.

Como os professores não poderiam dispensar seus alunos, as atividades iriam acontecer às sextas-feiras e aos sábados, sendo esse sábado considerado letivo. Para completar, deveria ficar um professor, ao menos, em cada escola, fora da formação. Esse 


\section{RevistAleph}

teria a função de ficar com os estudantes em uma programação interdisciplinar e coletiva. Assim, os estudantes não seriam prejudicados e os professores participariam da formação.

A secretaria municipal ficou responsável por um período do primeiro dia em todos os encontros, assim exporia suas demandas e ouviria as demandas dos docentes indígenas. Também seria responsável pela alimentação. O transporte seria por conta de cada formando. Já a hospedagem estaria por conta de cada comunidade que recebesse os cursistas.

Essa soma de esforços aconteceu, pois não havia verba à disposição, nem no IFBA nem na secretaria municipal. Contudo, esse esforço reforça a necessidade da formação. Inclusive, os professores eram unânimes em afirmar sobre o ineditismo dessa formação docente. Repetiam que sala multisseriada não era contemplada nas formações que chegavam.

Os mediadores da formação seriam professores do IFBA e os gestores da secretaria municipal. Sendo que os cursistas seriam também protagonistas, trazendo suas experiências e contribuindo para a construção de novas práticas de ensino e de aprendizagem.

Os temas definidos primavam pela alfabetização, letramento, numeramento e metodologias específicas para sala multisseriada. Os conteúdos escolhidos deveriam estar nesses temas e ser aplicados em forma de oficinas. Os professores não queriam somente teoria, esperavam debater novas metodologias, as quais culminariam em proposta de novas práticas pedagógicas.

Por fim, o projeto foi aprovado e os professores puderam se inscrever. A inscrição ficou sob a responsabilidade da seção de coordenação da educação escolar indígena da secretaria municipal.

Dos quatro encontros previstos para 2019, três aconteceram, não foi possível manter a meta de um por mês. Muitos fatores influenciaram na sustentação da atividade. Todos os empecilhos foram provenientes de questões étnicas ou de dificuldades impostas pelo clima. Inclusive, as intempéries não são previsíveis quando se está trabalhando com os movimentos sociais, mas devem ser consideradas para que não se interrompam as ações por motivos outros que certamente irão surgir. 


\section{RevistAleph}

O projeto ainda está em funcionamento neste ano de 2020, suspenso durante a pandemia de Covid 19. Contudo, pretende-se que vá até o final, mas sempre aceitando que as práticas sociais das comunidades indígenas exigem adequações no calendário.

Todas as decisões adotadas passaram pelo crivo dos três parceiros. Contudo, a função desse cuidado não foi somente respeitar o protagonismo, mas construir um projeto que respeitasse as especificidades dos Pataxó. Essas especificidades, quando não respeitadas, reduzem a probabilidade de sucesso.

Como previsto, a formação está acontecendo mais lentamente do que foi planejado, mas não precisou ser abandonada. A proposição coletiva, com os três entes participando, merece receber o crédito pela sustentação da formação.

\section{Protagonismo: Quem fala? Quem escuta? Quem propõe? Quem cumpre?}

O protagonismo na produção de conhecimento tem sido destinado, em geral, às universidades, institutos e centros de pesquisa. Esses locais estão incumbidos de erguer teorias, debates, práticas, conceitos, conhecimentos que ganham espaço na sociedade. Contudo, ganham espaço e sufocam outras formas de pensar e construir conhecimento. Inclusive classificam conhecimentos e definem os outros saberes como menores e menos confiáveis. Nossa discussão de saberes tradicionais e conhecimento científico se apoia em Cunha (2007) e Santos (2006), pois consideramos que o posicionamento de maneira desigual dessas duas categorias, colabora para o enfraquecimento das epistemologias dos grupos considerados minoritários.

Assim, ser protagonista é dispor de poder de decisão. É determinar o que deve e merece ser ensinado e aprendido. As instituições e os indivíduos com autorização social de construir conhecimento, também são portadores das licenças para questionar o conhecimento já prescrito e para propor mudanças em outros.

Não estão dentro desses espaços de decisão vários grupos sociais. Com isso, os grupos étnicos, os indígenas por exemplo, veem seus saberes e suas formas de transmitir conhecimento minimizados, invisibilizados e desconsiderados. Quando essa prática de hierarquização se torna naturalizada, perde-se a criticidade que deveria questionar essa forma de organizar ciência e conhecimento. Dentro das próprias comunidades tradicionais, 


\section{RevistAleph}

em suas escolas, a prática de escalonar qual conteúdo merece ser ensinado e aprendido recorre a julgamentos que tiveram suas bases definidas pelas comunidades envolvidas. Esse nivelamento acaba por confirmar o protagonismo de grupos ocidentais específicos, os quais continuam definindo que tem voz. Costa $(2012$, p. 127) mostra que os indígenas chegaram aos centros de formação, mas continuam enfrentando os 'sistemas' estruturais que os mantêm dentro das instituições, mas mudos e sem poder de decisão.

As comunidades indígenas sempre produziram suas epistemologias e suas maneiras de repassar para as gerações mais jovens esses conhecimentos. Contudo, não é difícil encontrar a separação nítida entre conhecimento (normalmente colocado para os grupos autorizados) e saberes (atribuído a grupos com menos poder simbólico). Costa $(2019$, p. 30) mostra que a construção de uma escola intercultural somente tem chances de se efetivar a partir do protagonismo do grupo indígena a ser atendido. Dessa forma, a relação dos centros de produção de conhecimento acadêmico ocidental com as comunidades indígenas corre sempre o risco de ser verticalizada. Criam-se dois lados: o lado da imposição, comandada por quem fala e se faz ouvir, as academias; o lado desprestigiado, que é obrigado a ouvir e não pode falar, comunidades tradicionais.

Resistentemente, o movimento indígena não acata esse espaço que the foi historicamente imposto. Após décadas de movimentação política, os indígenas conseguiram respeito por seu protagonismo. Protagonismo conquistado por meio de enfrentamentos, mas que colocou direitos para esses povos nesta carta magna. $\mathrm{Na}$ Constituição de 1988, no artigo 232, está expresso esse protagonismo e, a partir de então, mencioná-lo como elemento de base nas suas relações com os não indígenas é uma obrigatoriedade. Não se pode mais pensar nas relações que envolvem essas comunidades desconsiderando que a centralidade das questões a serem atacadas devem ser indicadas pelos povos que estão na outra ponta desse processo.

Assim, reconhecer que os saberes tradicionais são também conhecimentos merecedores do mesmo espaço oferecido ao saber científico não é, neste momento histórico, uma anomalia, muito pelo contrário, está se tornando uma maneira de repensar os grupos sociais. Ressaltemos que esse rearranjo não merece ser visualizado como uma outorga dos grupos com poderes hegemônicos aos demais grupos, pelo contrário, é uma conquista dos grupos étnicos. Contudo, essa postura ainda é minoritária, ou seja, hierarquizar, posicionando os conhecimentos ditos ocidentais como superiores aos demais, 


\section{RevistAleph}

ainda é a alternativa mais propagada e aceita. Essa parece uma afirmação de senso comum, mas na verdade é uma constatação vinda das experiências com os movimentos sociais.

Podemos, porém, afirmar que estamos em um momento de transição. As opções são caminhar para a mudança de paradigma ou descambar para a manutenção dos modelos majoritariamente vigentes. A depender dos movimentos indígenas, a mudança é a única possibilidade. Entretanto, há outra boa notícia, as instituições que fazem pesquisa no Brasil estão se aliando às comunidades tradicionais, mesmo que ainda não seja uma parceria como almejada pelos movimentos sociais, é uma união cada vez mais contundente e progressista. Para Paulo Freire, no livro organizado por Ana Maria Araújo Freire (2018, p. 56), "não é lutando pedagogicamente que vou mudar a pedagogia. Não são os filósofos da educação os que mudam a pedagogia, são os políticos sob nossa pressão que vão fazê-lo, se os pressionarmos". A comunidade indígena faz sua pressão e uma boa formação pode contribuir com essa coação para mudar toda uma prática social.

As Instituições de ensino superior estão assumindo, paulatinamente, uma postura de reconhecimento da importância de ações que envolvem os povos indígenas, por exemplo, estão percebendo que o protagonismo nessas ações não deve ser assumido pelas universidades e institutos, mas pelos indígenas. Assim, não basta ofertar um serviço, mesmo que esse seja solicitado, precisa-se perceber que a ação deve estar inserida dentro das reivindicações da comunidade indígena. Para Edson Kayapó (2019, p. 70) “é necessário conhecer quem são os povos indígenas, quantos são, onde vivem e como se relacionam com o Estado atualmente". Ou seja, os povos indígenas mantêm relações com agentes públicos e cobram seu direito político e constitucional de se representar.

O protagonismo da comunidade indígena regerá a relação com a instituição que ofertará a ação voltada para os grupos étnicos, qualquer outra forma de ação será enfraquecedora. Como defendido por Gersem Baniwa (2013), a presença de professores e técnicos indígenas nas escolas indígenas representa uma mudança em direção ao protagonismo. Na região de Porto Seguro, a quantidade de professores não indígenas nas escolas Pataxó é muito reduzida. Considerando essa presença e o movimento político que ela representa, o protagonismo das comunidades indígenas está se concretizando.

\section{As escolas multisseriadas e a formação continuada para docentes}




\section{RevistAleph}

No ano de 2018, os professores e as professoras da comunidade Pataxó requisitaram formação para sala multisseriada. Isso era esperado, pois a quantidade de salas multisseriadas nas escolas indígenas do município é muito superior à quantidade de sala de aula seriada. Contudo, toda a organização das escolas segue o padrão das escolas não indígenas, que são em sua maioria seriadas. Ao tomarem as rédeas do pedido da formação, os docentes confirmam a importância da ação que deve ser desenvolvida, pois eles são os sujeitos que "precisam urgentemente de se recontextualizarem na sua identidade e responsabilidades profissionais" (ALARCÃO, 2010, p. 34). Esses trabalhadores estão certamente ocupando um novo espaço. Isso significa, certamente, uma nova identidade.

O padrão que se mantém no ensino é de sala seriada. Estratégia comum quando se trata de sala multisseriada, já que o termo 'multisseriado', carrega 'seriado' em si (PEREIRA, MACEDO, 2018, p.158). A organização da jornada pedagógica das escolas indígenas, evento que ocorre uma vez ao ano, normalmente no início do ano letivo, não prioriza as classes multisseriadas. Mesmo que esse evento aconteça separado da jornada das escolas não indígenas, o modelo seriado prevalece, mesmo para as séries iniciais do ensino fundamental. Nessa etapa de ensino, a quantidade de salas multisseriadas nas escolas indígenas é superior às salas seriadas. Hage (2014) mostra uma realidade de escola do campo com multisseriação, mas podemos comparar com o que estamos debatendo aqui. Fica evidente na fala desse autor, que a desvalorização das escolas do campo progride para a desvalorização das práticas docentes e dos sujeitos que estudam nas escolas não urbanas. Essa realidade está presente nas escolas indígenas, porque enfrentam inúmeros desafios e acabam vendo seus esforços sendo desvalorizados.

O padrão que se mantém nas formações docentes é de sala seriada. Não é raro ver formações voltadas para os docentes indígenas. Contudo, é perceptível que se forma esses trabalhadores para salas de aula padrão, sendo que o padrão é a seriação. Quando se ignora uma prática social se ignora também as alternativas de mudança. A qualidade do ensino é proporcional a uma boa formação docente. Participar de debates que são preparados para uma realidade, um contexto social específico (sala com uma série/ano), mas ter de aplicálos em outra realidade, outro contexto, indica uma grande possibilidade de fracasso. Assim, 


\section{RevistAleph}

o docente fica incumbido de resolver por si só uma transposição bastante complicada, pegar um debate para um tipo de público e adaptá-lo para outro grupo. Para Hage:

No caso da condução do processo pedagógico, os professores se sentem angustiados quando assumem a visão da multissérie e tem que elaborar tantos planos e estratégias de ensino e avaliação diferenciados quanto forem às séries reunidas na turma; ação essa é fortalecida pelas secretarias de educação quando definem encaminhamentos pedagógicos e administrativos pedagógicos (HAGE, 2006, p. 4).

O padrão do livro didático e dos demais materiais didáticos também é para sala seriada. Os docentes precisam adaptar o livro didático e construir práticas a partir de um livro construído para sala com uma única série e, normalmente, considerando uma realidade não indígena e urbana. São muitas variantes para um processo que precisa atingir muitos objetivos, pois encara as expectativas de um público que acredita na escola. Assim, o sucesso que essas escolas alcançam deve ser creditado somente ao esforço desse grupo dedicado de trabalhadores. Deve-se considerar também a falta de tempo e de apoio que esses sujeitos enfrentam para conseguir elaborar seus próprios materiais.

O padrão que se mantém nas práticas pedagógicas também é de seriação. Sem formação adequada, sem materiais apropriadas, com uma escola que acredita que a seriação é o melhor caminho, as práticas pedagógicas acabam por buscar modelos na seriação. Para Zabala (1998, p. 15), o saber pedagógico deve receber especial atenção, pois influenciará muito diretamente no processo de ensino e aprendizagem. Quando se usa somente as experiências de vida dos educadores, aliadas à falta de diálogos que proponham alternativas ao que foi historicamente ofertado a esses trabalhadores, as metodologias que ganham espaço não são específicas, são normalmente voltadas para outras estruturas educacionais. As práticas docentes proporcionam a confirmação da aceitação dos modelos já impostos.

O padrão é seriação. Assim, a multisseriação se torna uma estrutura tratada como transitória, efêmera. A política mais adequada para esse tipo de classe é a luta para que deixe de existir, sendo substituída pela seriação. Nas conversas com os docentes, fica clara a vontade de se acabar com essa forma de organizar a escola. Logicamente, há um problema básico nessa maneira de encarar o ensalamento. Fica nítida a concepção de que basta se tornar seriada que não haverá mais dificuldades, que a qualidade da educação melhorará. Há um imaginário coletivo, que termina por considerar que com o tempo a população rural 


\section{RevistAleph}

seja extinta e, consequentemente, as escolas do campo deixariam de existir (DRUZIAN, MEURER, 2013), essa crença parece que está estendida às escolas indígenas e mais ainda às classes multisseriadas.

Será que as escolas seriadas estão com padrão de qualidade acima das salas multisseriadas? Difícil considerar que a resposta a essa pergunta seja uma constatação homogênea. Parece ser de senso comum que há várias escolas seriadas que não conseguem manter, ou alcançar, a qualidade que se espera. Entretanto, será que há escola multisseriada com qualidade? Com o quadro descrito até aqui, há muito mais chances de as salas seriadas atingirem o sucesso almejado, pois o apoio, mesmo capenga, quando acontece, vem ao estilo da seriação. Assim, logicamente, se as classes seriadas não estão conseguindo os objetivos almejados, estão ao menos com mais auxílio para chegar a eles.

Há um outro fator decisivo, não há um horizonte definido quando o assunto é o fim das classes multisseriadas. A quantidade de estudantes por série, que acaba sendo a principal justificativa dos gestores públicos para a não contratação de outros profissionais, não tende a atingir um patamar que vislumbre alteração. Assim, ao menos a maior parte das escolas que é multi hoje, tende a permanecer assim por um longo período. A vontade de mudança para seriação esbarra na política de contratação de docentes. Essa justificativa tende a ser forte inclusive para a manutenção do padrão típico da seriação nas escolas que não são seriadas.

Com todas essas desvantagens, buscar apoio para alterar esse quadro se torna a única alternativa. Contudo, surge um outro problema, o ato de aceitar as formações voltadas para a especificidade da multisseriação, tende a ser tratado pelos gestores das secretarias de educação como um problema em si, pois é visto como se tais gestores estivessem aceitando um tipo de sala de aula que não atingirá a qualidade esperada. Ou seja, a formação que considere tal especificidade lutará não só com a tarefa de mudar as práticas pedagógicas e seus materiais didáticos, mas terá de mudar o senso comum construído em torno desse tipo de escola. Um senso que tende a considerar como ruim qualquer forma de organizar a escola que seja diferente da seriada. Um senso que tem respaldo nas secretarias de educação, na sociedade escolarizada, nos docentes, nas

comunidades, é, portanto, bastante comum. Parente (2014) mostra uma realidade que compromete as contribuições que uma escola multisseriada pode trazer, não por si mesma, mas pela concepção que lhe é outorgada: 
É a compreensão errônea de que a escola multisseriada passaria necessariamente por um processo evolutivo, culminando na seriação, estágio mais avançado de organização da instituição escolar. Se pensarmos nas opções políticas em meio às quais nasceu a multisseriação, há certa lógica nessa abordagem. Mas, se pensarmos na própria crise do modelo seriado, desejar que o falacioso processo evolutivo da escola ocorra, será retroceder e negar as próprias oportunidades que surgem cotidianamente nas escolas multisseriadas, apesar do fardo nominal que carregam, apesar da ausência de políticas públicas para as populações do campo, apesar da demora em tratar os sujeitos dessas escolas como agentes na construção social da escola (PARENTE, 2014, p. 58).

Mudar a visão das pessoas quanto a sala multisseriada parece ser o único caminho para mudar essa realidade. Para que isso aconteça, primeiramente deve-se transformar a visão do docente sobre sua sala de aula. A qualidade do ensino, o tipo de sala, o material didático, as práticas docentes, os saberes presentes nos conteúdos, todos esses elementos precisam estar nos projetos políticos das escolas indígenas. Para D’Angelis (1999) somente um projeto político transformador levará à autonomia das sociedades indígenas. Neste projeto, estarão as indicações de formação, de produção de material didático, de participação da comunidade na escola. Todos esses elementos contribuirão para a construção da escola que a comunidade deseja.

A justificativa para que as salas de aula das escolas indígenas sejam multisseriadas não se limita à contratação de professores, mesmo que essa seja a mais forte, há ainda a questão da distância das escolas em relação à moradia das famílias. Na educação infantil e nas séries iniciais do ensino fundamental, as crianças não estão com idade para irem a lugares distantes de suas casas. Dessa forma, construir salas de aula mais próximas dessas comunidades é o melhor caminho.

Para se perceber o significado da distância nas comunidades indígenas, deve-se compreender que os territórios são amplos, com estradas sem pavimentação. Para as crianças chegarem sem atraso às aulas, teriam de sair muito cedo de casa e ainda enfrentar um transporte escolar precário. Esses fatores obrigam os pais a pedirem salas de aula mais próximas para seus filhos pequenos. Consequentemente, não há um elevado número de crianças próximas umas das outras, não alcançando um número considerado suficiente pelos gestores públicos para justificar a contratação de mais docentes.

A comunidade não acha razoável a alternativa à multisseriação. Expor seus filhos ao deslocamento diário não é visto como uma alternativa segura. Assim, a parceria da 


\section{RevistAleph}

comunidade indígena com centros de formação, para se buscar construir alternativas, parte do protagonismo indígena.

Por outro lado, as comunidades indígenas vivenciam experiências exitosas com escolas multisseriadas. Muitos dos seus estudantes, a maioria certamente, passaram por classes com essa estrutura. E vários conseguiram cumprir bem os processos de alfabetização, de letramento, de numeramento e prosseguiram seus estudos e suas interações sociais. Fica evidente que há histórias de sucesso calcadas nas classes não seriadas. Esse sucesso é outra justificativa para a construção da formação docente, da busca de parceria.

A comunidade Pataxó, no sul da Bahia, conta com muitas escolas multisseriadas e seus docentes articularam a formação para si. Foi a partir dessa articulação, vinda da comunidade, que foi construída a ação de extensão para sala multisseriada. Quando o grupo docente definiu a formação que queria receber, definiu também de que forma isso poderia ser articulado e quais conteúdos deveriam ser explorados. Concentraram-se em entender a multisseriação e em construir uma prática docente que abarcasse características para além do padrão da seriação.

O protagonismo estava bastante elencado, o quadro tenderia a ser bem mais gratificante para formandos e formadores. Obviamente a quantidade de escolas nesta região nos faz refletir sobre o quadro heterogêneo que será descortinado. Como mencionado por D’Angelis (2006, p. 159), “[...]uma escola indígena [pode] ser, nos casos extremos, muito distinta até mesmo de outra escola indígena a menos de $20 \mathrm{~km}$ de distância".

$\mathrm{Na}$ outra ponta da formação, em que se encontrava o Instituto Federal, este também era um protagonista. A diferença era o papel a ser exercido. O IFBA não teria a incumbência de definir por si só a formação a ser ofertada. A função dessa instituição estava na formatação dos debates científicos e dos saberes tradicionais para que o foco pudesse se manter na demanda já definida. Esse fator é bastante interessante e não retira protagonismo de ninguém. Até porque o poder de decidir qual o percurso a ser seguido, que coube ao instituto, é bastante forte. Ou seja, ainda seria possível ignorar a demanda em grande parte. Também seria possível fazer o debate pedido, mas utilizar bases teóricas que ignoram as comunidades tradicionais, essa postura é comum em muitos centros de formação. 


\section{RevistAleph}

Assim, a responsabilidade da instituição formadora quanto a manutenção dessa parceria, isso em bases isonômicas, é salutar. O descompasso do tratamento diferenciado presente na relação do saber tradicional com o conhecimento científico ainda se mantém. A sociedade tende a se manter firme em considerar como conhecimento o que foi testado e comprovado dentro dos centros autorizados para tal fim. Dessa forma, as formações continuadas de professores indígenas ainda esbarram no ranço da cientificidade versus saberes desvalorizados.

A postura de como o conhecimento será tratado dentro da instituição é, portanto, o principal entrave para a manutenção do protagonismo. Assim, a comunidade tradicional deve acompanhar a formação desde sua concepção até sua oferta, mantendo um momento de avaliação. Essa avaliação deve inclusive pensar sobre como o protagonismo da comunidade foi considerado. Ou seja, oferecer uma formação, como a que foi ofertada pelo IFBA, não é por si só um mérito para a instituição. Atinge esse patamar a partir do resultado alcançado e comprovado por meio da avaliação da ação. Essa avaliação deve ser empreendida em conjunto com a comunidade. Ressaltamos, porém, que os objetivos devem manter o protagonismo das comunidades como uma das metas a serem alcançadas.

Com essas premissas, já se pode construir uma nova política para sala multisseriada. As escolas que tratam a sala de aula multisseriada como aliada para a mudança na forma de ensinar existem. Deve-se enfatizar que nenhuma das escolas indígenas Pataxó é multisseriada por escolha, foi uma decisão imposta a partir de adequações às exigências das prefeituras. Esse fato torna mais trabalhosa a tarefa de colocar a multisseriação como uma opção viável.

Os docentes, então, ao pedir a formação específica para esse tipo de escola/sala de aula, discordam dos sujeitos que não veem esse tipo de escola como uma opção viável. Consideram, então, que há nelas a oportunidade de construir modelos didático pedagógicos específicos. Essa é também a direção que deve ser adotada pela instituição formadora. Neste caso, a instituição deve entender bem seu papel nessa relação, isso por meio de um processo reflexivo. Como mostrado por Nobre $(2009$, p. 26$)$, a escola se posiciona em um espaço bastante externo dentro da comunidade. É parte da comunidade, mas não é central como os rituais ou outras práticas culturais. Por outro lado, é preparada para o contato com o estrangeiro. A instituição escolhida para participar da formação, neste caso o IFBA, é esse estrangeiro. Esse fato define muito sobre como se posicionar. 


\section{RevistAleph}

É fato, portanto, que há escolas que escolheram ser multisseriadas. Neste grupo, normalmente, são citadas a escola SummerHill, na Inglaterra, a Escola da Ponte, em Portugal, o Colégio de Aplicação da UFRGS, em Porto Alegre (RS), e a escola Zeferino Lopes de Castro, em Viamão (RS). Se são consideradas boas escolas, há, então, a possibilidade de se construir um processo de ensino e aprendizagem que traga qualidade para a manutenção das estruturas que foram criadas em muitas escolas indígenas da região do extremo sul baiano. Inclusive, os professores, durante os primeiros encontros, fizeram questão de citar casos de sucesso de suas salas multisseriadas. Apresentando egressos que estavam em cursos superiores, pós-graduações, eram lideranças no povo e conseguiam interagir de forma intercultural com a comunidade envolvente.

Mais que resolver as questões de formação, essa ação de extensão abriu linhas de atuação para que o IFBA pudesse se fazer presente junto às comunidades Pataxó. Também mostrou a importância de haver linhas de escuta para construir outras ações. Por fim, a lição mais relevante foi mostrar que o protagonismo da comunidade tradicional não retira poderes da instituição que oferecerá a formação, mas acrescenta qualidade para uma relação equânime com os diversos setores da sociedade brasileira.

\section{Encerrando a conversa por enquanto}

As parcerias das universidades e institutos federais com as comunidades indígenas tendem a propiciar ganhos para ambos os lados. Para a experiência descrita neste texto, os ganhos são inegáveis. A quantidade de estudantes indígenas adentrando nos cursos superiores significou novas exigências para as instituições de ensino superior. Exigências positivas, pois significou cursos mais humanizados e preocupados com os públicos atendidos (COSTA, 2012). As comunidades também tiveram ganhos. Por exemplo, os professores indígenas voltaram das formações com mais conhecimentos técnicos e preparados para construir uma escola intercultural, bilíngue e específica para aquela comunidade.

O papel das instituições, então, está sendo definido ainda, mas a partir de novos parâmetros. Assim, serão novos modelos educacionais para atender novos sujeitos. Isso vale para o processo de ensino, pesquisa e extensão. Esses novos modelos estão considerando que o protagonismo das comunidades indígenas representa um ganho para 


\section{RevistAleph}

as instituições. As quais ainda não conseguiram ser um espaço para todos os grupos sociais. Pensar, portanto, no protagonismo indígena é descortinar-se para o protagonismo de outras comunidades, sejam elas quilombolas, ribeirinhas, ciganas, entre outras.

Desta forma, uma estrutura plural dentro das instituições de ensino superior tende a abrigar formações plurais. Todos serão beneficiados com centros de formação que considerem as especificidades de todos os grupos sociais. Assim, não é somente um caso de beneficiar grupos indígenas, mas aprender com a interação com os indígenas, neste caso os Pataxó, para criar formas outras de relação com a sociedade.

\section{Referências}

ALARCÃO, Isabel. Professores reflexivos em uma escola reflexiva. 7 ed. São Paulo: Cortez, 2010.

BANIWA, Gersem. Educação escolar indígena no Brasil: avanços, limites e novas perspectivas. 36ạ Reunião Nacional da ANPEd. Setembro/outubro de 2013. Goiânia-GO Disponível em: http://36reuniao.anped.org.br/pdfs_trabalhos_encomendados/gt21_trabalhoencomendado_gers em.pdf. Acesso em 17 de abril, 2020.

BARROS, Oscar Ferreira. A Organização do Trabalho Pedagógico das Escolas Multisseriadas: Indicativos de saberes pedagógicos de resistência educacional no campo. In: HAGE, Salomão Mufarrej (Org.). Educação do Campo na Amazônia: Retratos de realidade das escolas multisseriadas no Pará. Belém: Editora Gutemberg Ltda, 2005, pp. 163-195.

BRASIL, Constituição (1988). Constituição da República Federativa do Brasil: promulgada em 05 de outubro de 1988. Brasília: Senado Federal, Subsecretaria de Edições Técnicas, 2009.

COSTA, Francisco Vanderlei Ferreira da. Educação escolar indígena: um espaço intercultural em construção. In: COSTA, Francisco Vanderlei Ferreira da; FRANCO NETO, João Veridiano. Educação Escolar Indígena, interculturalidade e Memória. Araraquara: Letraria, 2019.

COSTA. Licenciatura Intercultural Indígena e novos currículos. In: ALVARENGA, Marcia Soares de et al (orgs.). Educação popular, movimentos sociais e formação de professores: outras questões, outros diálogos. Rio de Janeiro: EdUERJ, 2012.

CUNHA, Manuela Carneiro da. Relações e dissensões entre saberes tradicionais e saber científico. Revista USP, São Paulo, n.75, p. 76-84, setembro/novembro 2007.

D'ANGELIS, Wilmar da Rocha. Contra a ditadura da escola. In: GRUPIONI, Luís Donisete Benzi. Formação de professores indígenas: repensando trajetórias. Brasília: ministério da Educação, 2006.

D'ANGELIS, Wilmar da Rocha. Educação escolar indígena: um projeto étnico ou um projeto étnicopolítico? Texto apresentado no 12ㅇ COLE, UNICAMP, 1999. 


\section{RevistAleph}

DE MEDEIROS, Márcia Maria. A extensão Universitária no Brasil - Um percurso Histórico. Revista Barbaquá. Dourados - MS, vol. 01, n. 01, p. 09-16, jan-jun., 2017.

DRUZIAN, Franciele; MEURER, Ana Carine. Escola do campo multisseriada: experiência docente. Geografia Ensino \& Pesquisa, v. 17, n.2 p. 129-146, maio/ago. 2013.

FREIRE, Ana Maria Araújo. Pedagogia do compromisso: América Latina e Educação Popular. Rio de Janeiro/São Paulo: Paz e Terra, 2018.

FREIRE, Paulo. Educação e mudança. 34 ed. São Paulo: Paz e Terra, 2011.

FREIRE, Paulo. Pedagogia do oprimido. 50 ed. Rio de Janeiro: Paz e Terra, 2011.

HAGE, Salomão Antônio Mufarrej. Transgressão do paradigma da (multi)seriação como referência para a construção da escola pública do campo. Educação \& Sociedade, São Paulo, Cortez; Campinas, CEDES, v. 35, n. 129, p. 1165 - 1182, out./ dez., 2014.

HAGE, Salomão Antônio Mufarrej. (Org.). Educação do Campo na Amazônia: retratos de realidades das escolas multisseriadas no Pará. 1a Ed. Belém, 2006.

KAYAPÓ, Edson. A diversidade sociocultural dos povos indígenas no Brasil: o que a escola tem a ver com isso? In: SESC. Departamento Nacional de Culturas indígenas, diversidade e educação. Rio de Janeiro: Sesc, 2019.

NOBRE, Domingos. Uma pedagogia indígena Guarani na escola, pra quê?. Campinas: Curt Nimuendajú, 2009.

PARENTE, Cláudia da Mota Darós. Ensaio: aval. pol. públ. Educ., Rio de Janeiro, v.22, n. 82, p. 5788, jan./mar., 2014.

PEREIRA, Edirlene dos Santos; MACÊDO, Magda Martins. Escolas multisseriadas do campo: tempos, espaços e vivências. Revista Educação e Políticas em Debate - v. 7, n. 1, p. 152- 169 jan./abr. 2018.

SANTOS, Laymert Garcia dos. Saber tradicional X saber científico. In: Povo Indígenas no Brasil: 2001-2005. São Paulo: Instituto Socioambiental, 2006.

SERRANO, R. M. S. M. Conceitos de extensão universitária: um diálogo com Paulo Freire. In: Pró reitoria de extensão e assuntos comunitários - PRAC, João Pessoa, fev. 2006. Disponível em: www.prac.ufpb.br/copac/extelar/.../conceitos_de_extensao_universitaria.pdf. Acesso em: 16 março de 2020.

ZABALA, Antoni. A prática educativa: como ensinar. Porto Alegre: Artmed, 1998.

Data do envio: 20/04/2020

Data do aceite: $20 / 05 / 2020$. 